\title{
Targeted Treatment of Non-Small Cell Lung Cancer: Focus on Capmatinib with Companion Diagnostics
}

\author{
Matthew Z Guo (D) \\ Kristen A Marrone \\ Alexander Spira ${ }^{l-3}$ \\ David M Waterhouse W,4 $^{3}$ \\ Susan C Scott ${ }^{1}$ \\ 'Johns Hopkins University School of \\ Medicine, Sidney Kimmel Comprehensive \\ Cancer Center, Baltimore, MD, USA; \\ ${ }^{2}$ Virginia Cancer Specialists Research \\ Institute, Fairfax, VA, USA; ${ }^{3}$ US \\ Oncology, The Woodlands, TX, USA; \\ ${ }^{4}$ Oncology Hematology Care, Cincinnati, \\ $\mathrm{OH}$, Usa
}

\begin{abstract}
M E T$ dysregulation promoting tumorigenesis in non-small cell lung cancer (NSCLC) is associated with worse outcomes following chemotherapy as compared to nondriver mutated NSCLC and occurs either through mutations causing MET exon 14 skipping (METex14) or gene amplification and overexpression that result in enhanced receptor signaling. Capmatinib is the first FDA-approved targeted therapy for NSCLC with METex14 skipping mutations, approved in 2020. FoundationOne ${ }^{\circledR} \mathrm{CDx}$, a comprehensive genomic profiling test for solid tumors, was concurrently approved as a companion diagnostic for capmatinib use. The GEOMETRY mono-1 phase II trial of capmatinib monotherapy demonstrated an overall response rate (ORR) of $68 \%$ in treatment naïve $(n=28)$ and $41 \%$ in pre-treated $(\mathrm{n}=69)$ METex 14 skipping advanced NSCLC; in MET amplified advanced NSCLC (gene copy number $\geq 10$ ) ORRs of $40 \%$ in treatment naïve and $29 \%$ in pre-treated disease was seen. This review outlines the clinical data supporting capmatinib approval in the treatment of NSCLC and FoundationOne ${ }^{\circledR}$ CDx approval as a companion diagnostic. We detail the practical clinical administration of capmatinib, including dosing and toxicity management, compare capmatinib to other approved and investigational MET-targeted therapies, discuss limitations of capmatinib, and highlight ongoing trials of capmatinib in combinatorial approaches.
\end{abstract}

Keywords: capmatinib, MET exon 14 skipping, non-small cell lung cancer, FoundationOne $\mathrm{CDx}$

\section{Introduction}

In the era of precision oncology, many patients with NSCLC have benefited from an increasing number of targeted therapies against common driver mutations. At the same time, the field of cancer diagnostics is growing apace with molecular techniques like next-generation sequencing (NGS) that have paved the way for individualized cancer treatment in the clinic. New targeted therapies and companion diagnostics are being rapidly developed and approved for oncogene driven cancers that have previously lacked effective treatments, including NSCLC driven by aberrant MET activity.

$M E T$ is a proto-oncogene that contributes to both de novo tumorigenesis and drugresistance in NSCLC due to gain-of-function alterations including METex14 or MET gene amplification. ${ }^{1}$ Following results from the phase II GEOMETRY mono-1 openlabel, multicenter clinical trial, capmatinib received accelerated FDA-approval in May 2020, alongside FoundationOne ${ }^{\circledR}$ CDx, as the first targeted therapy and companion
Correspondence: Susan C Scott Johns Hopkins University School of Medicine, Sidney Kimmel Comprehensive Cancer Center, 20I N Broadway,

Baltimore, MD, 21287 , USA

Tel + |4| 0-955-8893

Fax +|4|0-367-2| 94

Email sscott89@jhmi.edu 
diagnostic for METex14 skipping NSCLC. ${ }^{2}$ In this review, we outline the preclinical, clinical, and safety data of capmatinib and describe data supporting FoundationOne CDx test as the companion diagnostic to capmatinib for METex14 NSCLC. We also discuss current ongoing trials and future directions for this promising therapeutic agent and alternative therapies for MET-driven NSCLC to provide clinical context for using capmatinib in this rapidly evolving field.

\section{Pathogenesis, Diagnosis, and Prevalence of MET Alterations in NSCLC}

Mesenchymal-epithelial transition (MET), a transmembrane receptor tyrosine kinase that binds the ligand hepatocyte growth factor (HGF), is expressed in many epithelial cell types and plays diverse roles in development and tissue regeneration. ${ }^{3}$ In normal tissue, homodimerization and phosphorylation of MET results in activation of downstream RAS, PI3K-AKT, Wnt, and STAT growth signaling pathways. In MET-altered tumors, over-activation of these downstream pathways contributes to oncogenesis (Figure 1).
MET dysregulation is both a primary oncogenic driver and a secondary resistance mechanism in many cancers contributing to tumor cell growth, survival, and invasion. ${ }^{5}$ Two primary molecular mechanisms underlie oncogenic MET alterations: mutations causing $M E T$ exon 14 skipping and $M E T$ gene amplification, which have similar tumorigenic effects, yet distinct diagnostic and therapeutic considerations. METex 14 skipping is a gain-of-function mutation caused by a wide variety of genetic alterations in splice sites surrounding exon 14 or within exon 14, which encodes a juxtamembrane domain ubiquitination site that acts as a key negative regulatory element to promote receptor degradation and prevent MET oversignaling., ${ }^{6,7}$ This group of somatic mutations promotes aberrant $M E T$ transcription with fusion of exons 13 and 15, resulting in exclusion of the regulatory domain and upregulated signaling by the mutant MET receptor. ${ }^{8}$ Due to the diversity of mutations causing METex14 skipping, NGS, which detects the various splice site mutations, and RT-PCR, which detects the truncated template after

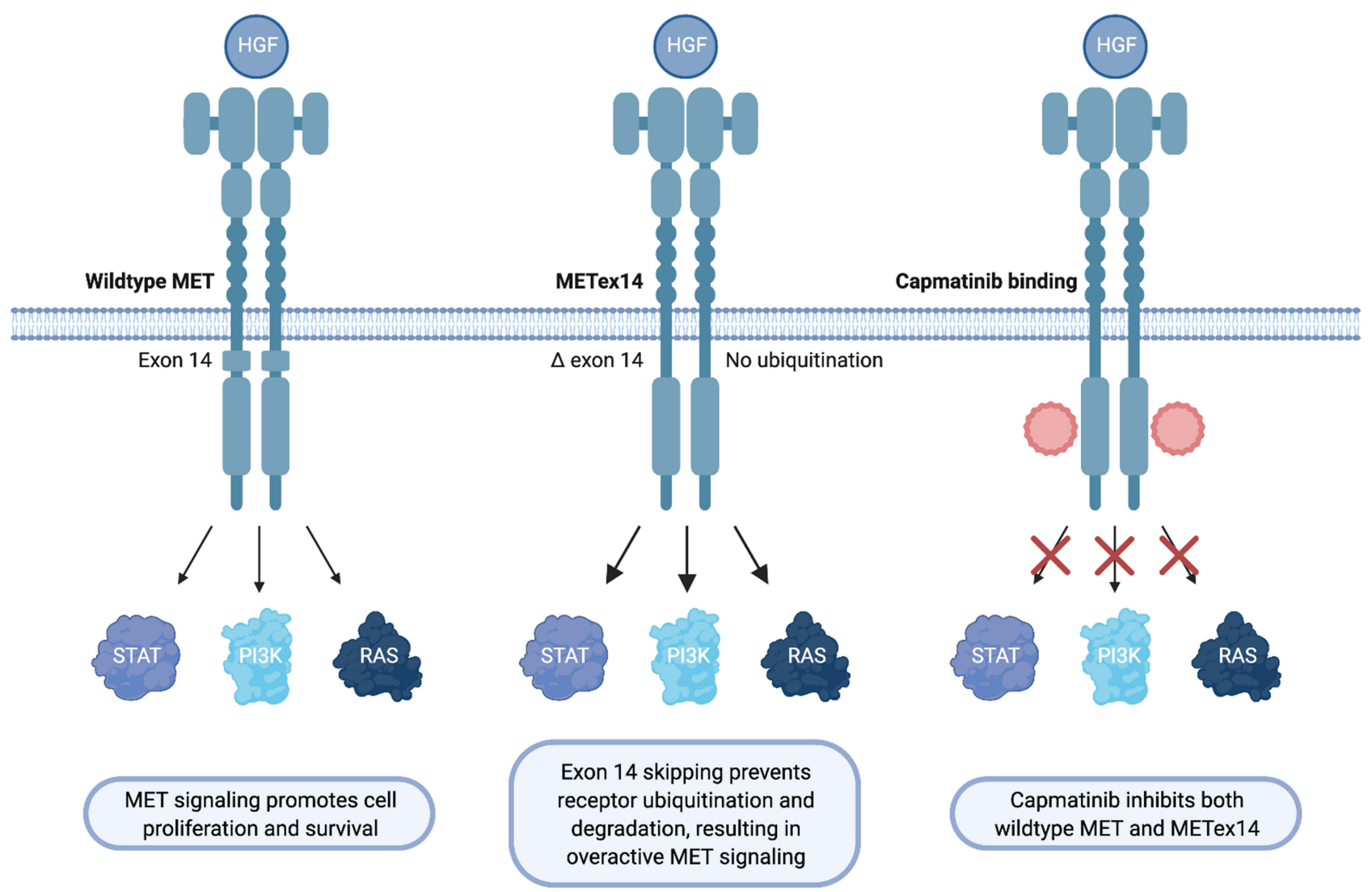

Figure I Capmatinib selectively targets MET on NSCLC tumor cells, inhibiting both wildtype and METex/4 which lacks ubiquitination sites required for receptor degradation. 
alternative splicing, are the most sensitive and comprehensive diagnostic tools for these mutations. ${ }^{8,9}$ Diagnosis of MET amplification is defined by fluorescence in-situ hybridization (FISH) analysis reporting $M E T$-to-chromosome 7 centromere (MET/CEP7) ratio or NGS reporting gene copy number $(\mathrm{GCN})$ per cell. A previous study seeking to define $M E T$ amplification analyzed the mean $M E T /$ cell and mean $M E T / C E P 7$ using FISH in 686 cases of NSCLC. The authors defined high amplification as $M E T /$ cell $\geq 7$ or MET/ $C E P 7 \geq 5$, intermediate amplification as $M E T /$ cell $\geq 6$ to $<7$ or $M E T / C E P 7>2.2$ to $<5$, and low amplification as $M E T /$ cell $\geq 5$ to $<6$ or $M E T / C E P 7 \geq 1.8$ to $\leq 2.2$. MET/cell $<5$ and $M E T / C E P 7<1.8$ were defined as no amplification. While the boundaries of amplification levels differ widely in the field, using these author-defined breakdowns between high, intermediate, and low amplification, the authors concluded that $M E T /$ cell $\geq 7$ or $M E T /$ $C E P 7 \geq 5$ were associated with the strongest responses to MET inhibition. They thus concluded that these diagnostic criteria are indicative of high MET amplification. ${ }^{10}$

In NSCLC, MET dysregulation is a prognostic biomarker associated with poorer outcomes. ${ }^{11-13}$ METex 14 most frequently presents as a primary driver mutation, occurring in $3-4 \%$ of patients with NSCLC overall and $8-22 \%$ of patients with the rare NSCLC subtype pulmonary sarcomatoid carcinoma. ${ }^{7,14-16}$ The frequency of MET amplification in NSCLC is difficult to define given the varied definitions and cutoffs applied, but in one comprehensive analysis, $M E T$ amplification defined as $M E T / C E P 7 \geq 2.0$ or $M E T /$ cell $\geq 6$ occurred de novo in approximately $3 \%$ of treatment-naive patients with NSCLC. ${ }^{17}$ MET amplification occurs more commonly as a resistance mechanism in approximately $20 \%$ of patients on anti-EGFR TKI therapies. ${ }^{17,18}$ Concurrent MET amplification occurs in 15-21\% of METex14 NSCLC, ${ }^{14,19}$ while other driver mutations (ie, EGFR, ALK, ROS1, BRAF) are rarely found in METex14 tumors, ${ }^{19}$ suggesting that METex14 skipping is an independent driver of oncogenesis. Brain metastases develop in $20-40 \%$ of patients with METex 14 NSCLC, a frequency similar to that of all stage IV NSCLC $^{20,21}$ Despite the prevalence of MET-driven NSCLC, prior to the approval of capmatinib for METex14 NSCLC in May 2020, targeted treatment had been primarily limited to off-label use of multi-kinase inhibitors crizotinib and cabozantinib.

\section{Capmatinib for the Treatment of METex I4 Skipping and MET Amplified NSCLC}

Capmatinib is a type I MET inhibitor with high potency $\left(\mathrm{IC}_{50}=0.13 \mathrm{nmol} / \mathrm{L}\right)$ and selectivity. ${ }^{22}$ The ATPcompetitive TKI binds to both wild-type and exon 14 skipped MET protein products (Figure 1) and demonstrated selectivity for MET kinase and its disease variants in a screen of over 400 candidate kinases. ${ }^{23}$ The medication is orally bioavailable and is metabolized primarily by CYP3A4 and aldehyde oxidase. ${ }^{24}$

Preclinical studies of capmatinib found that it effectively inhibited MET receptor signaling, halting tumor growth and inducing apoptosis. Capmatinib displayed activity in mouse xenograft models bearing tumors from lung and liver cancers with METex14 or MET amplification. ${ }^{22,23}$ Treatment with capmatinib also restored sensitivity to erlotinib, an anti-EGFR TKI, in NSCLC cell lines that had acquired resistance post-TKI. ${ }^{25}$ Interestingly, in vivo experiments studying capmatinib in combination with standard chemotherapy in mice found that capmatinib not only increased the antitumor efficacies of cisplatin and doxorubicin but also limited their respective nephrotoxicity and cardiotoxicity. ${ }^{26}$

A Phase I trial of capmatinib in MET-positive advanced NSCLC and other solid tumors determined the recommended Phase 2 dose of $400 \mathrm{mg}$ tablets BID or $600 \mathrm{mg}$ capsules BID. ${ }^{27,28}$ The study demonstrated safety and clinical activity in predominantly pretreated patients (95\% had received at least one prior line of systemic therapy) with various MET alterations including METex14 and amplification with GCN $\geq 6 .{ }^{27}$ The most common adverse events (AEs) were GI-related toxicities and peripheral edema.

The therapeutic role of capmatinib in METex14 NSCLC was further established in the stage II, multicenter, open-label GEOMETRY mono-1 trial (NCT02414139) studying capmatinib in 364 patients in various cohorts segregated by METex14 status, MET amplification status, and number of previous systemic therapies (Table 1). ${ }^{29}$ The strongest responses to capmatinib were in patients with treatment naïve METex14 NSCLC with an objective response rate (ORR) of $68 \%$, median duration of response (DOR) of 12.6 months, and median progression-free survival of (PFS) 12.4 months. Treatment naïve NSCLC patients with high MET amplification (GCN $\geq 10$ ) also had robust responses to 
Table I Responses to Capmatinib by NSCLC Cohort from GEOMETRY mono-I ${ }^{29}$

\begin{tabular}{|l|l|l|l|l|}
\hline Cohort & MET Alteration & Previous Treatment & ORR & Median DOR (Months) \\
\hline Cohort Ia $(n=69)$ & Amplification GCN $\geq 10$ & Pretreated & $29 \%$ & 8.3 \\
Cohort Ib $(n=42)$ & Amplification GCN 6-9 & Pretreated & $12 \%$ & 24.9 \\
Cohort 2 $(n=54)$ & Amplification GCN 4-5 & Pretreated & $9 \%$ & 9.7 \\
Cohort 3 $(n=30)$ & Amplification GCN <4 & Pretreated & $7 \%$ & 4.2 \\
Cohort 4 $(n=69)$ & METexI4 any GCN & Pretreated & $41 \%$ & 9.7 \\
Cohort 5a $(n=15)$ & Amplification GCN $\geq 10$ & Treatment naïv & $40 \%$ & 7.5 \\
Cohort 5b $(n=28)$ & METexI4 any GCN & Treatment naive & $68 \%$ & 12.6 \\
\hline
\end{tabular}

Notes: From Wolf J, Seto T, Han J-Y, et al. Capmatinib in MET exon 14-mutated or MET-amplified non-small-cell lung cancer. N Engl J Med. 2020;383(I0):944-957. Copyright (c) 2020 Massachusetts Medical Society. Reprinted with permission from Massachusetts Medical Society. ${ }^{29}$

capmatinib (ORR 40\%, median DOR 7.5 months, median PFS 4.2 months). ${ }^{29}$ Interim analysis of an expansion cohort, pretreated METex 14 or GCN $\geq 10$ patients $(\mathrm{n}=$ 34 ), revealed an ORR of $48 \%$, and an additional cohort of treatment naïve METex14 patients $(\mathrm{n}=23)$ is currently ongoing. ${ }^{29}$

Intracranial disease control of capmatinib was observed in 12 out of 13 response-evaluable patients in the GEOMETRY mono-1 trial with brain metastases at baseline. Seven of the 12 patients had an intracranial response, including four complete responses. ${ }^{29}$ The observed intracranial activity of capmatinib thus addressed a treatment limitation of MET-dysregulated NSCLC with crizotinib, which has poor blood-brain barrier penetration. ${ }^{30}$

The most common AEs of any grade observed in the GEOMETRY mono-1 trial were peripheral edema (51\%) and nausea (45\%). Additional AEs occurring in more than $20 \%$ of patients included vomiting, increased serum creatinine, dyspnea, fatigue, and decreased appetite. Treatment-related AEs grade $\geq 3$ occurred in 13\% of patients, most commonly peripheral edema, dyspnea, and increased ALT. Dose reduction occurred in $23 \%$ of patients and discontinuation in $11 \%$. One death due to pneumonitis was attributed to capmatinib treatment. ${ }^{29}$

A retrospective study of a subset of patients screened for the GEOMETRY mono-1 in Korea observed a median overall survival (OS) of 21.5 months among 8 patients with MET-driven tumors (METex14 or GCN $\geq 10$ ) treated with capmatinib, as compared to median OS of 7.5 months for MET-driven tumors treated with standard chemotherapy regimens $(\mathrm{n}=6)$, and 11.3 months among $M E T$ wildtype controls $(n=53)$ on standard chemotherapy. ${ }^{31}$ This analysis highlights the ability of targeted therapy with capmatinib to overcome the poorer prognosis of $M E T$ dysregulated NSCLC.
Other clinical studies have focused on capmatinib as a salvage therapy for patients with MET-driven tumors who progress on standard TKIs. Among 15 patients with METex14 and 5 patients with MET amplified NSCLC pretreated with crizotinib, ORR to capmatinib was $10 \%$, but disease control rate (DCR) was $80 \%$, including stable disease in all 4 patients with intracranial metastases. Based on these modest results, the authors of the study suggest that capmatinib and crizotinib may have overlapping resistance mechanisms. ${ }^{32}$

\section{FoundationOne ${ }^{\circledR} \mathrm{CDx}$ as the Companion Diagnostic for Capmatinib in METex I4 NSCLC}

Prior to the approval of capmatinib, there was no approved standardized, comprehensive platform for diagnosing METex14 mutations, a challenging task given the diverse array of splice site mutations that could lead to exon truncation. FoundationOne CDx, an NGS-based diagnostic tool indicated and validated for all solid tumors, is currently the only FDA-approved companion diagnostic for capmatinib for METex14 NSCLC. ${ }^{2}$

FoundationOne CDx utilizes DNA extracted from formalin-fixed, paraffin-embedded tumor tissue specimens to detect indels and single nucleotide variants in 324 genes. FoundationOne CDx also reports on selected clinically relevant gene rearrangements, tumor microsatellite instability, and tumor mutational burden. ${ }^{2}$ FoundationOne also offers a liquid biopsy diagnostic tool for cell-free tumor DNA (cfDNA) circulating in plasma, however this platform is not currently approved to identify METex 14 skipping mutations. ${ }^{33}$ Several institutions globally have conducted studies examining the clinical utility and costefficiency of FoundationOne CDx, finding that test utilization enhanced delivery of precision therapy with minimal 
budget impact. These studies found that the utilization of comprehensive genomic testing for NSCLC had a budget impact per person per year of $\$ 0.71-0.8$ with a 3 -year gain of 680.9 life-years. FoundationOne CDx was found to have a $96.7 \%$ success rate, with earlier NGS testing maximizing clinical benefit. These studies prompted FoundationOne CDx to become a companion diagnostic for capmatinib for MET-dysregulated NSCLC. ${ }^{34-36}$ Utilization of FoundationOne CDx as a companion diagnostic for other driver mutations in other solid tumors is currently being investigated, with mixed results suggesting potential applications in glioma and breast but limited utility in pancreatic ductal adenocarcinoma. ${ }^{37-39}$

\section{Clinical Administration of Capmatinib and Management of Toxicities}

Capmatinib is administered orally as $400 \mathrm{mg}$ tablets BID or $600 \mathrm{mg}$ capsules BID. The most prominent AEs associated with capmatinib treatment are nausea and peripheral edema. Other common AEs (defined as $<20 \%$ ) include diarrhea, fatigue, decreased appetite, and increased blood creatinine levels. Dyspnea occurs less commonly but was a treatment-related $\mathrm{AE}$ that contributed to the death of one patient in a phase Ib/II study of capmatinib plus gefitinib. $^{40}$

Early management of low-grade toxicities is recommended to mitigate against more severe toxicities and preserve the ability to continue capmatinib therapy. Dose reductions first to $300 \mathrm{mg} \mathrm{BID}$, then to $200 \mathrm{mg}$ BID, with permanent discontinuation if $200 \mathrm{mg}$ BID remains intolerable, are recommended for adverse event management. ${ }^{24}$

Peripheral edema and GI toxicity are recognized as class effects associated with MET inhibitors. Low grade peripheral edema can be treated initially with compression stockings, mobility, leg elevation, and dietary salt modification. Higher grade peripheral edema may require capmatinib dose reduction, and clinicians can consider trial of spironolactone or furosemide. ${ }^{24,41,42}$ Taking capmatinib with food is recommended as studies with and without food restriction found that taking capmatinib with food decreased the incidence of GI toxicity without decreasing drug exposure. ${ }^{29}$

Patients should be closely monitored for symptoms of interstitial lung disease (ILD) and pneumonitis, such as dyspnea, cough, and fever. Any grade ILD/pneumonitis merits permanent treatment discontinuation if no other cause is identified due to the risk of death. ${ }^{24,42}$

Grade 3 hepatotoxicity with increased ALT and/or AST without increased total bilirubin merits withholding treatment until liver function has recovered to baseline followed by dose continuation or reduction. Treatment should be permanently discontinued for grade 4 hepatotoxicity, or grade 3 hepatotoxicity with increased total bilirubin. $^{24}$

Capmatinib inhibits renal transporters MATE1 and MATE2-K causing the observed reversible elevated blood creatinine. $^{29}$ Although this may make the determination of renal function more challenging, increases in blood creatinine $>3$ times the upper limit of normal were not reported, and no dosage adjustment was recommended with $\mathrm{CrCl}$ above $30 \mathrm{~mL} / \mathrm{min}$.

Capmatinib can increase the risk of photosensitivity, and so proper preventative and precautionary measures are indicated. Patients should mitigate ultraviolet exposure and utilize sunscreen and protective clothing. Finally, pregnant females should be advised of the risk of fetal harm, and both males and females with reproductive potential should be advised to use effective contraception while on capmatinib and for at least one week after ending capmatinib therapy. ${ }^{42}$

\section{Capmatinib in Ongoing and Future Trials}

A Phase III study GEOMETRY-III (NCT04427072) of capmatinib vs docetaxel in pre-treated patients with METex14 NSCLC began in September 2020. This study should provide further insight into how capmatinib compares to cytotoxic chemotherapy in the second line. ${ }^{43}$

Another area of interest for MET-targeted therapy is in patients with EGFR-driven tumors that develop MET amplification, a predominant bypass resistance mechanism in anti-EGFR TKI therapy. One early-phase trial combined capmatinib and gefitinib as salvage treatment in patients with acquired resistance to gefitinib, erlotinib, or afatinib, and found that the regimen was tolerable and observed an ORR of $27 \%$ with median DOR of 5.6 months and DCR of $73 \% .{ }^{40}$ In patients with high MET-amplified tumors (GCN $\geq 6$ ) the ORR was $47 \%$. Similarly, a case report described that capmatinib combined with high-dose osimertinib (160 mg) induced improvement both clinically and radiologically in one patient with EGFR-mutant NSCLC with secondary MET amplification who had previously 
progressed on erlotinib, high-dose osimertinib, carboplatin plus pemetrexed, atezolizumab, and crizotinib. ${ }^{44}$ The use of capmatinib combinations in post-EGFR TKI resistance is under further investigation in a phase III trial GEOMETRY-E (NCT04816214) studying capmatinib plus osimertinib vs platinum-pemetrexed doublet chemotherapy in the second line for EGFR-mutant, MET amplified NSCLC. ${ }^{45}$ Combination therapy with capmatinib plus nazartinib, a current investigational thirdgeneration anti-EGFR TKI that binds EGFR T790 similar to osimertinib, ${ }^{46,47}$ is also being investigated in a phase $\mathrm{Ib} /$ II study (NCT02335944) in NSCLC patients with EGFR mutations. $^{48}$

Capmatinib has also been implicated as an immunomodulatory agent through stabilization of PD-1, resulting in decreased $\mathrm{T}$ cell antitumor activity. ${ }^{49}$ Immune checkpoint inhibitors such as nivolumab are known to overcome PD-1-mediated T cell anergy and promote antitumor activity. Preliminary findings presented at the 2020 IASLC Meeting from a phase II study (NCT02323126) of capmatinib plus nivolumab found an ORR of $25 \%$ in MET GCN $\geq 5$ NSCLC patients $(\mathrm{n}=16)$ and an ORR $17 \%$ in all other patients $(\mathrm{n}=30) .{ }^{50}$ The addition of anti-PD-1 agent spartalizumab to capmatinib for METex14 NSCLC in the first line is also under investigation in a randomized phase II trial NCT04323436. ${ }^{51}$ Another phase II study (NCT04139317) is comparing pembrolizumab plus capmatinib to pembrolizumab alone in patients with NSCLC with PD-L1 expression $>50 \% .^{52}$ Overall, these studies will better characterize the anti-tumor effects of immune checkpoint inhibitors in combination with capmatinib.

As $M E T$ dysregulation is a driver mutation and potentially an actionable biomarker in multiple cancers, capmatinib is also under investigation in other solid tumors with MET mutations such as advanced hepatocellular carcinoma (NCT01737827), glioblastoma multiforme (NCT02386826), and papillary renal cell cancer (NCT02019693). As more mature evidence for other tumor types is awaited, capmatinib in METex14 NSCLC remains the only approved MET-specific targeted therapy.

\section{Comparisons to Other MET Targeted Therapies}

Many novel targeted therapies are in the pipeline to address MET dysregulation as an independent oncogenic driver as well as a secondary resistance mechanism to
EGFR-TKI therapy in NSCLC and other cancers (Table 2).

Crizotinib is a multi-kinase inhibitor approved for the treatment of advanced ALK and ROS-1 driven NSCLC, with activity against MET. In the PROFILE 1001 study, crizotinib resulted in an ORR of $32 \%$ in METex14 (n=65) and $38 \%$ in $M E T$ amplified ( $\mathrm{n}=38$ ) tumors $(\mathrm{GCN} \geq 7$ ). Median duration of response was 9.1 months and median PFS of 7.3 months for patients with METex 14 tumors. ${ }^{53,54}$ Cabozantinib is another non-selective TKI with reported activity and off-label use in MET-driven NSCLC, currently under investigation in the Italian CABinMET study (NCT03911193) in subjects with tumors harboring METex14 mutations or MET amplification. ${ }^{55}$

The phase II VISION study of tepotinib in METex 14 skipping NSCLC found an ORR 46\% and median DOR 11.1 months. $^{56}$ The phase Ib/II INSIGHT study (NCT01982955) found tepotinib plus gefitinib to be superior to platinum-pemetrexed duet chemotherapy (ORR 45\% vs 33\%) for pretreated EGFR-positive NSCLC, particularly for tumors with $M E T$ amplification. ${ }^{57}$ The most common AEs in tepotinib included peripheral edema and elevated serum amylase. Grade $\geq 3$ TRAEs occurred in $28 \%$ of patients, in contrast to $37 \%$ of patients receiving capmatinib in the GEOMETRY mono-1 trial. The VISION and INSIGHT trials, along with three separately published case reports, have also indicated that tepotinib has intracranial activity. ${ }^{56-60}$ These findings prompted FDA accelerated approval for tepotinib for METex14 skipping NSCLC in February 2021. ${ }^{61}$ Future studies evaluating genomic or other clinical determinants of response may help better differentiate the two promising drugs.

Savolitinib is a MET-selective TKI that has activity in METex 14 pulmonary sarcomatoid carcinoma, an NSCLC histology enriched for METex14, and other NSCLCs. Preliminary data from a phase II trial (NCT02897479) found an ORR of $47.5 \%$ and median DOR not reached among 61 evaluable patients, with similar AEs including peripheral edema, nausea and vomiting, elevated AST/ ALT, and hypoalbuminemia. ${ }^{62}$ CNS activity of savolitinib is yet to be fully described. For secondary MET amplification in pretreated EGFR-mutated NSCLC, the combination of savolitinib plus osimertinib achieved an ORR of $48 \%$ with median DOR of 9.5 months. ${ }^{63}$ The results of this trial as well as the capmatinib plus osimertinib and capmatinib plus nazartinib trials are highly anticipated to understand whether the MET selective TKIs are tolerable and effective in combination with third-generation EGFR TKIs. 
Table 2 Clinical Trials Investigating Monotherapies for METexI4 NSCLC

\begin{tabular}{|l|l|l|l|l|l|l|l|}
\hline Drug & Trial & Phase & N & $\begin{array}{l}\text { Mechanism } \\
\text { of Action }\end{array}$ & $\begin{array}{l}\text { ORR for Treatment Naïve } \\
\text { METex I4 NSCLC }\end{array}$ & $\begin{array}{l}\text { ORR for Pretreated } \\
\text { METexI 4 NSCLC }\end{array}$ & $\begin{array}{l}\text { Grade } \geq \\
\text { 3 TRAEs }\end{array}$ \\
\hline Capmatinib $^{29}$ & $\begin{array}{l}\text { GEOMETRY } \\
\text { mono-I }\end{array}$ & II & 364 & $\begin{array}{l}\text { Selective MET } \\
\text { TKI }\end{array}$ & $68 \%$ & $41 \%$ & $37 \%$ \\
\hline Crizotinib $^{53}$ & PROFILE I00I & I & 65 & $\begin{array}{l}\text { Multikinase } \\
\text { TKI }\end{array}$ & $25 \%$ & $37 \%$ & $29 \%$ \\
\hline Tepotinib $^{56}$ & VISION & II & 152 & $\begin{array}{l}\text { Selective MET } \\
\text { TKI }\end{array}$ & $44 \%$ & $48 \%$ & $28 \%$ \\
\hline Savolitinib $^{62}$ & NCT02897479 & II & 70 & $\begin{array}{l}\text { Selective MET } \\
\text { TKI }\end{array}$ & $46 \%$ & $40 \%$ & $41 \%$ \\
\hline Bozitinib $^{64}$ & NCT0289623I & I & $1 \mathrm{I}$ & $\begin{array}{l}\text { Selective MET } \\
\text { TKI }\end{array}$ & NA & $67 \%$ & $27 \%$ \\
\hline
\end{tabular}

Bozitinib, another MET selective TKI, achieved an ORR of $31 \%$ in patients with MET dysregulated NSCLC, though subgroup analysis found that METex 14 and MET amplification cohorts had higher ORRs at $67 \%$ and $41 \%$, respectively, as compared to MET overexpression. Treatment AEs that occurred in more than $20 \%$ of patients included ALT/AST increase, bilirubinemia, peripheral edema, and QTc elongation. ${ }^{64}$ This study excluded patients with brain metastases, so intracranial of bozitinib has not yet been assessed.

Two novel multi-kinase inhibitors with MET activity, glesatinib and merestinib, are under study for MET-driven NSCLC. ${ }^{65,66}$ Glesatinib and merestinib are ATP-competitive type II MET TKIs that bind to the adenine-binding site, while capmatinib is an ATP-competitive type I MET TKI that interacts with the Y1230 residue to lock the kinase in an autoinhibitory conformation. ${ }^{67}$ Glesatinib is of particular interest as it was found to have activity in vitro against MET with D1228 and Y1230 mutations that are typically associated with METTKI resistance. ${ }^{66}$ In pretreated NSCLC, ORR to glesatinib was $14 \%$ in 36 patients with MET activating mutations and $9 \%$ in 32 patients with $M E T$ gene amplifications. Common AEs were similar to those of capmatinib and included diarrhea, nausea/ vomiting, fatigue, increased ALT/AST, peripheral edema, fatigue, dyspnea, hypokalemia, and hypomagnesemia. ${ }^{68}$ Merestinib demonstrated safety and clinical efficacy in a phase I trial and is currently being studied in a phase II study of pretreated METex14 NSCLC (NCT02920996). ${ }^{69}$ Intracranial activity has not been assessed for either merestinib or glesatinib.

Several antibody-based anti-MET therapies are in development and under investigation at NSCLC as well. Of note, antibody-based therapies require IV infusion, which may represent a barrier compared to capmatinib, an oral medication. Telisotuzumab vedotin (teliso-v) is an antibody-drug conjugate (ADC) coupling an anti-MET antibody with the tubulin inhibitor MMAE. In pretreated patients with $E G F R$ wild-type NSCLC, telisotuzumab vedotin achieved an ORR of 54\% in a MET-high expressing cohort and 25\% in a MET-intermediate cohort. $^{70}$

Amivantamab is a bispecific EGFR/MET antibody that received FDA accelerated approval for EGFR exon 20 insertion mutated NSCLC, and the ongoing CHRYSALIS trial explores its use in MET dysregulated NSCLC in both METex14 and post-EGFR-TKI MET amplified cohorts. ${ }^{71}$ Emibetuzumab is a bivalent MET/MET antibody that, when added to first-line erlotinib, increases ORR from $66 \%$ to $85 \%$ in EGFR-mutated NSCLC. ${ }^{72}$ Another bivalent MET/MET antibody, REGN5093, is currently being studied in a first-in-human phase I/II trial for METex14 or MET amplified NSCLC. ${ }^{73}$ Sym015, an antagonistic antibody mixture of two non-overlapping anti-MET monoclonal antibodies, has demonstrated promising antitumor effects in preclinical models. ${ }^{74}$ A phase Ia/IIa trial found ORRs of $25 \%$ for both METex14 and MET amplified NSCLC, ${ }^{75}$ suggesting that unlike for capmatinib, METex14 skipping mutations do not prognosticate for superior outcomes with Sym015 treatment as compared to other MET dysregulations. All these antibodies are expected to have poor blood-brain barrier penetration, and so further studies, potentially in combination with capmatinib or other TKIs, will provide greater insight into their utilities in targeting MET dysregulated NSCLC. 


\section{Limitations and Resistance to Capmatinib}

As an anti-MET TKI, capmatinib can be selected for resistance due to alterations in MET kinase, bypass pathway activation, or ligand upregulation. Mutations in D1228 of the kinase domain and Y1230 of the activation loop have been identified as mechanisms of resistance in patients who progress on capmatinib treatment. ${ }^{32,76,77}$ Alterations in MAPK, EGFR, and KRAS, as well as upregulation of the MET ligand HGF have also been suggested as potential bypass pathway mechanisms for anti-MET TKI therapy. ${ }^{78-81}$ Treatment of post-capmatinib may thus require switching to a type II TKI (eg cabozantinib, glesatinib, merestinib), which are hypothesized to have activity against D1228 and Y1230 mutations, bypass pathway targeted therapy, or anti-HGF therapy. ${ }^{82,83}$

\section{Conclusion}

As the first FDA-approved targeted therapy and companion diagnostic for NSCLC with METex14 skipping mutations, capmatinib and FoundationOne ${ }^{\circledR} \mathrm{CDx}$ address an unmet need in oncology for the diagnosis and treatment of tumors with METex14 skipping mutations. Furthermore, MET-directed therapy with capmatinib has demonstrated efficacy in tumors with MET amplification, both de novo amplification and secondary amplification most commonly observed as a mechanism of anti-EGFR TKI resistance, though it is not yet approved for use in these settings. The toxicity profile of capmatinib is manageable, with peripheral edema and nausea most commonly reported across all anti-MET TKIs. Compared to other MET TKIs under investigation, capmatinib demonstrates robust clinical efficacy with similar toxicity profiles. Ongoing studies of capmatinib in combination therapy with immune checkpoint inhibitors and anti-EGFR TKIs and will be closely followed to better characterize the role of capmatinib in treating MET-driven NSCLC.

\section{Acknowledgments}

No funding was provided for this work. Figure created by author MG using BioRender.com subscription.

\section{Disclosure}

MZG and SCS have no financial or non-financial disclosures. KAM has received consulting fees from AstraZeneca and Amgen.
- Honoraria: AstraZeneca

- Consulting fees: AstraZeneca, Amgen, Puma Biotechnology, Janssen, Mirati Therapeutics

- Research funding (institution): Bristol-Myers Squibb, AstraZeneca

AS disclosures

- Stock and other ownership interests: Eli Lilly

- Honoraria: CytomX Therapeutics, AstraZeneca/ MedImmune, Merck, Takeda, Amgen, Janssen Oncology, Novartis, Bristol-Myers Squibb, Bayer

- Consulting fees: Incyte, Amgen, Novartis, Mirati Therapeutics, Gritstone Oncology, Jazz Pharmaceuticals, Takeda

- Consulting (institution): Array BioPharma, AstraZeneca/ MedImmune, Merck, Bristol-Myers Squibb

- Research funding: LAM Therapeutics

- Research funding (institution): Roche, AstraZeneca, Boehringer Ingelheim, Astellas Pharma, MedImmune, Novartis, Newlink Genetics, Incyte, AbbVie, Ignyta, LAM Therapeutics, Trovagene, Takeda, Macrogenics, CytomX Therapeutics, Astex Pharmaceuticals, Bristol-Myers Squibb, Loxo, Arch Therapeutics, Gritstone, Plexxikon, Amgen, Daiichi Sankyo, ADCT, Janssen Oncology, Mirati Therapeutics, Rubius.

DMW disclosures

- Consulting fees: Bristol-Myers Squibb, AZTherapies, AbbVie, Amgen, McGivenny Global, Janssen Oncology, Seattle Genetics, Jazz Pharmaceuticals, Exelixis, Eisai, EMD Serono, Merck, Pfizer, Mirati Therapeutics, Regeneron/Sanofi

- Speakers' bureau: Bristol-Myers Squibb, Janssen Oncology, Merck, AstraZeneca, Amgen, EMD Serono.

\section{References}

1. Drilon A, Cappuzzo F, Ou S-HI, Camidge DR. Targeting MET in lung cancer: will expectations finally be MET? J Thorac Oncol. 2017;12 (1):15-26. doi:10.1016/j.jtho.2016.10.014

2. Foundation medicine receives FDA approval for FoundationOne ${ }^{\circledR} \mathrm{CDx}$ as the companion diagnostic for tabrecta ${ }^{\mathrm{TM}}$ (capmatinib), the only FDA-approved MET inhibitor for patients with metastatic non-small cell lung cancer with METex14. Available from: https://www.foundationmedicine.com/press-releases /0f19426e-6c6b-4d75-8801-789b6f603eb2. Accessed November 6, 2021. 
3. Organ SL, Tsao M-S. An overview of the c-MET signaling pathway. Ther Adv Med Oncol. 2011;3(1 Suppl):S7-S19. doi:10.1177/ 1758834011422556

4. Sierra JR, Tsao M-S. c-MET as a potential therapeutic target and biomarker in cancer. Ther Adv Med Oncol. 2011;3(1 Suppl):S21-S35. doi:10.1177/1758834011422557

5. Zhang Y, Xia M, Jin K, et al. Function of the c-Met receptor tyrosine kinase in carcinogenesis and associated therapeutic opportunities. Mol Cancer. 2018;17(1):45. doi:10.1186/s12943-018-0796-y

6. Pilotto S, Gkountakos A, Carbognin L, Scarpa A, Tortora G, Bria E. MET exon 14 juxtamembrane splicing mutations: clinical and therapeutical perspectives for cancer therapy. Ann Transl Med. 2017;5 (1):2. doi:10.21037/atm.2016.12.33

7. Onozato R, Kosaka T, Kuwano H, Sekido Y, Yatabe Y, Mitsudomi T. Activation of MET by gene amplification or by splice mutations deleting the juxtamembrane domain in primary resected lung cancers. $J$ Thorac Oncol. 2009;4(1):5-11. doi:10.1097/JTO.0b013e3181913e0e

8. Davies KD, Lomboy A, Lawrence CA, et al. DNA-based versus RNA-based detection of MET exon 14 skipping events in lung cancer. $J$ Thorac Oncol. 2019;14(4):737-741. doi:10.1016/j. jtho.2018.12.020

9. Drilon A. MET exon 14 alterations in lung cancer: exon skipping extends half-life. Clin Cancer Res. 2016;22(12):2832-2834. doi:10.1158/1078-0432.CCR-16-0229

10. Noonan SA, Berry L, Lu X, et al. Identifying the appropriate FISH criteria for defining MET copy number-driven lung adenocarcinoma through oncogene overlap analysis. J Thorac Oncol. 2016;11 (8):1293-1304. doi:10.1016/j.jtho.2016.04.033

11. Vuong HG, Ho ATN, Altibi AMA, Nakazawa T, Katoh R, Kondo T. Clinicopathological implications of MET exon 14 mutations in non-small cell lung cancer - A systematic review and meta-analysis. Lung Cancer Amst Neth. 2018;123:76-82. doi:10.1016/j. lungcan.2018.07.006

12. Go H, Jeon YK, Park HJ, Sung S-W, Seo J-W, Chung DH. High MET gene copy number leads to shorter survival in patients with non-small cell lung cancer. $J$ Thorac Oncol. 2010;5(3):305-313. doi:10.1097/JTO.0b013e3181ce3d1d

13. Guo B, Cen H, Tan X, Liu W, Ke Q. Prognostic value of MET gene copy number and protein expression in patients with surgically resected non-small cell lung cancer: a meta-analysis of published literatures. Coleman WB, ed. PLoS One. 2014;9(6):e99399. doi:10.1371/journal.pone.0099399

14. Awad MM, Oxnard GR, Jackman DM, et al. MET exon 14 mutations in non-small-cell lung cancer are associated with advanced age and stage-Dependent MET genomic amplification and c-Met overexpression. J Clin Oncol. 2016;34(7):721-730. doi:10.1200/ JCO.2015.63.4600

15. Liu X, Jia Y, Stoopler MB, et al. Next-generation sequencing of pulmonary sarcomatoid carcinoma reveals high frequency of actionable MET gene mutations. J Clin Oncol. 2016;34(8):794-802. doi:10.1200/JCO.2015.62.0674

16. Schrock AB, Frampton GM, Suh J, et al. Characterization of 298 patients with lung cancer harboring MET exon 14 skipping alterations. $J$ Thorac Oncol. 2016;11(9):1493-1502. doi:10.1016/j.jtho.2016.06.004

17. Schildhaus H-U, Schultheis AM, Rüschoff J, et al. MET amplification status in therapy-naïve adeno- and squamous cell carcinomas of the lung. Clin Cancer Res. 2015;21(4):907-915. doi:10.1158/1078-0432. CCR-14-0450

18. Cappuzzo F, Jänne PA, Skokan M, et al. MET increased gene copy number and primary resistance to gefitinib therapy in non-small-cell lung cancer patients. Ann Oncol. 2009;20(2):298-304. doi:10.1093/ annonc/mdn635

19. Tong JH, Yeung SF, Chan AWH, et al. MET amplification and exon 14 splice site mutation define unique molecular subgroups of non-small cell lung carcinoma with poor prognosis. Clin Cancer Res. 2016;22(12):3048-3056. doi:10.1158/1078-0432.CCR-15-2061
20. Ali A, Goffin JR, Arnold A, Ellis PM. Survival of patients with non-small-cell lung cancer after a diagnosis of brain metastases. Curr Oncol Tor Ont. 2013;20(4):e300-306. doi:10.3747/co.20.1481

21. Awad MM, Leonardi GC, Kravets S, et al. Impact of MET inhibitors on survival among patients with non-small cell lung cancer harboring MET exon 14 mutations: a retrospective analysis. Lung Cancer Amst Neth. 2019;133:96-102. doi:10.1016/j.lungcan.2019.05.011

22. Liu X, Wang Q, Yang G, et al. A novel kinase inhibitor, INCB28060, blocks c-MET-dependent signaling, neoplastic activities, and cross-talk with EGFR and HER-3. Clin Cancer Res. 2011;17 (22):7127-7138. doi:10.1158/1078-0432.CCR-11-1157

23. Baltschukat S, Engstler BS, Huang A, et al. Capmatinib (INC280) is active against models of non-small cell lung cancer and other cancer types with defined mechanisms of MET activation. Clin Cancer Res. 2019;25(10):3164-3175. doi:10.1158/1078-0432.CCR-18-2814

24. TABRECTATM (capmatinib) tablets, for oral use. Available from: https://www.accessdata.fda.gov/drugsatfda_docs/label/2020/ 213591s0001bl.pdf. Accessed November 6, 2021.

25. Lara MS, Holland WS, Chinn D, et al. Preclinical evaluation of MET inhibitor INC-280 with or without the epidermal growth factor receptor inhibitor erlotinib in non-small-cell lung cancer. Clin Lung Cancer. 2017;18(3):281-285. doi:10.1016/j.cllc.2016.11.006

26. Shaker ME, Shaaban AA, El-Shafey MM, El-Mesery ME. The selective c-Met inhibitor capmatinib offsets cisplatin-nephrotoxicity and doxorubicin-cardiotoxicity and improves their anticancer efficacies. Toxicol Appl Pharmacol. 2020;398:115018. doi:10.1016/j. taap. 2020.115018

27. Schuler M, Berardi R, Lim W-T, et al. Molecular correlates of response to capmatinib in advanced non-small-cell lung cancer: clinical and biomarker results from a phase I trial. Ann Oncol. 2020;31 (6):789-797. doi:10.1016/j.annonc.2020.03.293

28. Bang Y, Su W, Schuler M, et al. Phase 1 study of capmatinib in METpositive solid tumor patients: dose escalation and expansion of selected cohorts. Cancer Sci. 2020;111(2):536-547. doi:10.1111/ cas. 14254

29. Wolf J, Seto T, Han J-Y, et al. Capmatinib in MET exon 14-mutated or MET-amplified non-small-cell lung cancer. $N$ Engl J Med. 2020;383(10):944-957. doi:10.1056/NEJMoa2002787

30. Morris TA, Khoo C, Solomon BJ. Targeting ROS1 rearrangements in non-small cell lung cancer: crizotinib and newer generation tyrosine kinase inhibitors. Drugs. 2019;79(12):1277-1286. doi:10.1007/ s40265-019-01164-3

31. Choi W, Park S-Y, Lee Y, et al. The clinical impact of capmatinib in the treatment of advanced non-small cell lung cancer with MET exon 14 skipping mutation or gene amplification. Cancer Res Treat. 2021;53(4):1024-1032. doi:10.4143/crt.2020.1331

32. Dagogo-Jack I, Moonsamy P, Gainor JF, et al. A phase 2 study of capmatinib in patients with MET-altered lung cancer previously treated with a MET inhibitor. J Thorac Oncol. 2021;16(5):850-859. doi:10.1016/j.jtho.2021.01.1605

33. FoundationOne ${ }^{\circledR}$ Liquid CDx. Available from: https://www.founda tionmedicine.com/test/foundationone-liquid-cdx. Accessed November 6, 2021.

34. Johnston KM, Sheffield BS, Yip S, Lakzadeh P, Qian C, Nam J. Comprehensive genomic profiling for non-small-cell lung cancer: health and budget impact. Curr Oncol Tor Ont. 2020;27(6):e569e577. doi:10.3747/co.27.5995

35. Inagaki $\mathrm{C}$, Maeda $\mathrm{D}$, Hatake $\mathrm{K}$, et al. Clinical utility of next-generation sequencing-based panel testing under the universal health-care system in Japan: a retrospective analysis at a single university hospital. Cancers. 2021;13(5):1121. doi:10.3390/ cancers 13051121

36. Takeda M, Takahama T, Sakai K, et al. Clinical application of the FoundationOne $\mathrm{CDx}$ assay to therapeutic decision-making for patients with advanced solid tumors. Oncologist. 2021;26(4):e588e596. doi:10.1002/onco.13639 
37. Sharaf R, Pavlick DC, Frampton GM, et al. FoundationOne CDx testing accurately determines whole arm $1 \mathrm{p} 19 \mathrm{q}$ codeletion status in gliomas. Neuro-Oncol Adv. 2021;3(1):vdab017. doi:10.1093/noajn1/ vdab017

38. Kawaji H, Kubo M, Yamashita N, et al. Comprehensive molecular profiling broadens treatment options for breast cancer patients. Cancer Med. 2021;10(2):529-539. doi:10.1002/cam4.3619

39. Kimura R, Ohtsuka T, Kubo M, et al. FoundationOne ${ }^{\circledR}$ CDx gene profiling in Japanese pancreatic ductal adenocarcinoma patients: a single-institution experience. Surg Today. 2021;51(4):619-626. doi:10.1007/s00595-020-02123-2

40. Wu Y-L, Zhang L, Kim D-W, et al. Phase Ib/II study of capmatinib (INC280) plus gefitinib after failure of epidermal growth factor receptor (EGFR) inhibitor therapy in patients with EGFR-mutated, MET factor-dysregulated non-small-cell lung cancer. J Clin Oncol. 2018;36(31):3101-3109. doi:10.1200/JCO.2018.77.7326

41. Lyudmila Bazhenova, Joshua Bauml, Benjamin Levy. MET Inhibitors in NSCLC: Toxicity Management. Presented at: April 19, 2019; OncLive. Available from: https://www.onclive.com/view/metinhibitors-in-nsclc-toxicity-management.

42. Safety, dosing, and administration tabrecta. Available from: https:// www.hcp.novartis.com/siteassets/tabrecta/tabrecta-hcp-safety-dosingguide.pdf. Accessed November 6, 2021.

43. Study of capmatinib efficacy in comparison with docetaxel in previously treated participants with non-small cell lung cancer harboring MET exon 14 skipping mutation (GeoMETry-III). Available from: https://clinicaltrials.gov/ct2/show/NCT04427072. Accessed November 6, 2021.

44. Gautschi O, Menon R, Bertrand M, Murer C, Diebold J. Capmatinib and osimertinib combination therapy for EGFR-mutant lung adenocarcinoma. J Thorac Oncol. 2020;15(1):e13-e15. doi:10.1016/j.jtho.2019.07.027

45. Study evaluating efficacy and safety of capmatinib in combination with osimertinib in adult subjects with non-small cell lung cancers as second line therapy (GEOMETRY-E). Available from: https:// clinicaltrials.gov/ct2/show/NCT04816214. Accessed November 6, 2021.

46. Tan DS-W, Leighl NB, Riely GJ, et al. Safety and efficacy of nazartinib (EGF816) in adults with EGFR-mutant non-small-cell lung carcinoma: a multicentre, open-label, phase 1 study. Lancet Respir Med. 2020;8(6):561-572. doi:10.1016/S2213-2600(19) 30267-X

47. Jia Y, Juarez J, Li J, et al. EGF816 exerts anticancer effects in non-small cell lung cancer by irreversibly and selectively targeting primary and acquired activating mutations in the EGF receptor. Cancer Res. 2016;76(6):1591-1602. doi:10.1158/0008-5472.CAN$15-2581$

48. Study of safety and efficacy of EGFR-TKI EGF816 in combination with cMET inhibitor INC280 in non-small cell lung cancer patients with EGFR mutation. Available from: https://www.clinicaltrials.gov/ ct2/show/study/NCT02335944. Accessed November 6, 2021.

49. Li H, Li C-W, Li X, et al. MET inhibitors promote liver tumor evasion of the immune response by stabilizing PDL1. Gastroenterology. 2019;156(6):1849-1861.e13. doi:10.1053/j. gastro.2019.01.252

50. Felip E. Efficacy and safety of capmatinib plus nivolumab in pretreated patients with EGFR wild-type non-small cell lung cancer. Poster presented at the: 2020 World Conference on Lung Cancer; January 28; 2021; IASLC. Available from: https://ibrary.iaslc.org/ conference-program?product_id $=20 \&$ author $=\&$ category $=\&$ date $=$ $\&$ session_type $=\& \operatorname{session}=\&$ presentation $=\&$ keyword $=$ capmati nib\&cme $=$ undefined $\&$.

51. Study of capmatinib and spartalizumab/placebo in advanced NSCLC patients with MET exon 14 skipping mutations. Available from: https://www.clinicaltrials.gov/ct2/show/NCT04323436. Accessed November 6, 2021.
52. Safety and efficacy of capmatinib (INC280) plus pembrolizumab vs pembrolizumab alone in NSCLC with PD-L1 $\geq 50 \%$. Available from: https://clinicaltrials.gov/ct2/show/study/NCT04139317. Accessed November 6, 2021.

53. Drilon A, Clark JW, Weiss J, et al. Antitumor activity of crizotinib in lung cancers harboring a MET exon 14 alteration. Nat Med. 2020;26 (1):47-51. doi:10.1038/s41591-019-0716-8

54. Camidge DR, Otterson GA, Clark JW, et al. Crizotinib in patients with MET-amplified NSCLC. $J$ Thorac Oncol. 2021;16 (6):1017-1029. doi:10.1016/j.jtho.2021.02.010

55. D'Arcangelo M, Tassinari D, De Marinis F, et al. P2.01-15 phase II single arm study of CABozantinib in non-small cell lung cancer patients with MET deregulation (CABinMET). J Thorac Oncol. 2019;14(10):S644. doi:10.1016/j.jtho.2019.08.1359

56. Paik PK, Felip E, Veillon R, et al. Tepotinib in non-small-cell lung cancer with $M E T$ exon 14 skipping mutations. $N$ Engl J Med. 2020;383(10):931-943. doi:10.1056/NEJMoa2004407

57. Wu Y-L, Cheng Y, Zhou J, et al. Tepotinib plus gefitinib in patients with EGFR-mutant non-small-cell lung cancer with MET overexpression or MET amplification and acquired resistance to previous EGFR inhibitor (INSIGHT study): an open-label, phase 1b/2, multicentre, randomised trial. Lancet Respir Med. 2020;8(11):1132-1143. doi:10.1016/S2213-2600(20)30154-5

58. Roth KG, Mambetsariev I, Salgia R. Prolonged survival and response to tepotinib in a non-small-cell lung cancer patient with brain metastases harboring MET exon 14 mutation: a research report. Cold Spring Harb Mol Case Stud. 2020;6(6):a005785. doi:10.1101/mcs.a005785

59. Blanc-Durand F, Alameddine R, Iafrate AJ, et al. Tepotinib efficacy in a patient with non-small cell lung cancer with brain metastasis harboring an HLA-DRB1-MET gene fusion. Oncologist. 2020;25 (11):916-920. doi:10.1634/theoncologist.2020-0502

60. Takamori S, Matsubara T, Fujishita T, et al. Dramatic intracranial response to tepotinib in a patient with lung adenocarcinoma harboring MET exon 14 skipping mutation. Thorac Cancer. 2021;12 (6):978-980. doi:10.1111/1759-7714.13871

61. FDA grants accelerated approval to tepotinib for metastatic non-small cell lung cancer. Available from: https://www.fda.gov/drugs/drugapprovals-and-databases/fda-grants-accelerated-approval-tepotinibmetastatic-non-small-cell-lung-cancer. Accessed November 6, 2021.

62. Lu S, Fang J, Li X, et al. Phase II study of savolitinib in patients (pts) with pulmonary sarcomatoid carcinoma (PSC) and other types of non-small cell lung cancer (NSCLC) harboring MET exon 14 skipping mutations (METex14+). J Clin Oncol. 2020;38(15_suppl):9519. doi:10.1200/JCO.2020.38.15_suppl.9519

63. Sequist LV, Han J-Y, Ahn M-J, et al. Osimertinib plus savolitinib in patients with EGFR mutation-positive, MET-amplified, non-small-cell lung cancer after progression on EGFR tyrosine kinase inhibitors: interim results from a multicentre, open-label, phase $1 \mathrm{~b}$ study. Lancet Oncol. 2020;21(3):373-386. doi:10.1016/S1470-2045(19)30785-5

64. Yang J, Zhou Q, Chen H, et al. Abstract CT127: a phase I study of cMET inhibitor bozitinib in patients with advanced NSCLC harboring $c M E T$ alterations. Tumor Biology. American Association for Cancer Research; 2020:CT127-CT127. doi:10.1158/1538-7445.AM2020-CT127

65. Yan SB, Um SL, Peek VL, et al. MET-targeting antibody (emibetuzumab) and kinase inhibitor (merestinib) as single agent or in combination in a cancer model bearing MET exon 14 skipping. Invest New Drugs. 2018;36(4):536-544. doi:10.1007/s10637-017-0545-x

66. Engstrom LD, Aranda R, Lee M, et al. Glesatinib exhibits antitumor activity in lung cancer models and patients harboring MET exon 14 mutations and overcomes mutation-mediated resistance to type I MET inhibitors in nonclinical models. Clin Cancer Res. 2017;23 (21):6661-6672. doi:10.1158/1078-0432.CCR-17-1192

67. Reungwetwattana T, Liang Y, Zhu V, Ou S-HI. The race to target MET exon 14 skipping alterations in non-small cell lung cancer: the why, the how, the who, the unknown, and the inevitable. Lung Cancer. 2017;103:27-37. doi:10.1016/j.lungcan.2016.11.011 
68. Phase 2 study of MGCD265 in patients with non-small cell lung cancer with activating genetic alterations in MET. Available from: https:/clinicaltrials.gov/ct2/show/results/NCT02544633. Accessed November 6, 2021.

69. Merestinib in non-small cell lung cancer and solid tumors. Available from: $\quad$ https://clinicaltrials.gov/ct2/show/study/NCT02920996. Accessed November 6, 2021.

70. Camidge DR. CT179 - Telisotuzumab vedotin (teliso-v) monotherapy in patients with previously treated c-Met+ advanced non-small cell lung cancer. Poster presented at the: AACR Annual Meeting 2021; April 10; 2021; IASLC. Available from: https://www.abstractsonline. com/pp8/\#!/9325/presentation/5250.

71. Guo MZ, Marrone KA, Spira A, Freeman K, Scott SC. Amivantamab: a potent novel EGFR/c-MET bispecific antibody therapy for EGFR-mutated non-small cell lung cancer. Oncol Haematol. 2021;17(1):42-47. doi:10.17925/OHR.2021.17.1.42

72. Scagliotti G, Moro-Sibilot D, Kollmeier J, et al. A randomizedcontrolled phase 2 study of the MET antibody emibetuzumab in combination with erlotinib as first-line treatment for EGFR mutation-positive NSCLC patients. J Thorac Oncol. 2020;15(1):80-90. doi:10.1016/j.jtho.2019.10.003

73. Rowlands T, Boyapati A, Li S, et al. A phase I/II study of REGN5093, a MET x MET bispecific antibody, in patients with MET-altered advanced non-small cell lung cancer (NSCLC). J Clin Oncol. 2020;38 (15_suppl):TPS9628. doi:10.1200/JCO.2020.38.15_suppl.TPS9628

74. Poulsen TT, Grandal MM, Skartved NJØ, et al. Sym015: a highly efficacious antibody mixture against MET-amplified tumors. Clin Cancer Res. 2017;23(19):5923-5935. doi:10.1158/1078-0432.CCR-17-0782

75. Camidge DR, Janku F, Martinez-Bueno A, et al. Safety and preliminary clinical activity of the MET antibody mixture, Sym015 in advanced non-small cell lung cancer (NSCLC) patients with MET amplification/exon 14 deletion (MET Amp/Ex14ム $)$. J Clin Oncol. 2020;38(15_suppl):9510. doi:10.1200/JCO.2020.38.15_suppl.9510

76. Qi J, McTigue MA, Rogers A, et al. Multiple mutations and bypass mechanisms can contribute to development of acquired resistance to MET inhibitors. Cancer Res. 2011;71(3):1081-1091. doi:10.1158/ 0008-5472.CAN-10-1623
77. Tiedt R, Degenkolbe E, Furet P, et al. A drug resistance screen using a selective MET inhibitor reveals a spectrum of mutations that partially overlap with activating mutations found in cancer patients. Cancer Res. 2011;71(15):5255-5264. doi:10.1158/0008-5472.CAN$10-4433$

78. Recondo G, Bahcall M, Spurr LF, et al. Molecular mechanisms of acquired resistance to MET tyrosine kinase inhibitors in patients with MET exon 14-mutant NSCLC. Clin Cancer Res. 2020;26 (11):2615-2625. doi:10.1158/1078-0432.CCR-19-3608

79. Rotow JK, Gui P, Wu W, et al. Co-occurring alterations in the RASMAPK pathway limit response to MET inhibitor treatment in MET exon 14 skipping mutation-positive lung cancer. Clin Cancer Res. 2020;26(2):439-449. doi:10.1158/1078-0432.CCR-19-1667

80. Suzawa K, Offin M, Lu D, et al. Activation of KRAS mediates resistance to targeted therapy in MET exon 14-mutant non-small cell lung cancer. Clin Cancer Res. 2019;25(4):1248-1260. doi:10.1158/1078-0432.CCR-18-1640

81. Pennacchietti S, Cazzanti M, Bertotti A, et al. Microenvironmentderived HGF overcomes genetically determined sensitivity to anti-MET drugs. Cancer Res. 2014;74(22):6598-6609. doi:10.1158/ 0008-5472.CAN-14-0761

82. Bahcall M, Sim T, Paweletz CP, et al. Acquired $M E T^{\mathrm{D} 1228 \mathrm{~V}}$ mutation and resistance to MET inhibition in lung cancer. Cancer Discov. 2016;6(12):1334-1341. doi:10.1158/2159-8290.CD-16-0686

83. Mok TSK, Park K, Geater SL, et al. A randomized phase (PH) 2 study with exploratory biomarker analysis of ficlatuzumab (F) a humanized hepatocyte growth factor (HGF) inhibitory MAB in combination with gefitinib (G) versus $G$ in asian patients (PTS) with lung adenocarcinoma (LA). Ann Oncol. 2012;23:ix391. doi:10.1016/S0923-7534(20)33782-0
OncoTargets and Therapy

\section{Publish your work in this journal}

OncoTargets and Therapy is an international, peer-reviewed, open access journal focusing on the pathological basis of all cancers, potential targets for therapy and treatment protocols employed to improve the management of cancer patients. The journal also focuses on the impact of management programs and new therapeutic
Dovepress

agents and protocols on patient perspectives such as quality of life, adherence and satisfaction. The manuscript management system is completely online and includes a very quick and fair peer-review system, which is all easy to use. Visit http://www.dovepress.com/ testimonials.php to read real quotes from published authors. 